\title{
Immunohistochemical Study on Gonadotropin-Releasing Hormone Neurons in the Shiba Goat Brain
}

\author{
Tomohiro HAMADA, Takeo SHIMIZU, \\ Masumi ICHIKAWA ${ }^{1)}$ and Yuji MORI ${ }^{2}$ \\ Laboratory of Veterinary Reproduction, \\ Tokyo University of Agriculture and Technology, \\ Fuchu, Tokyo 183, 1)Department of Anatomy \\ and Embryology, Tokyo Metropolitan Institute \\ for Neuroscience, Fuchu, Tokyo 183, and \\ 2) Laboratory of Veterinary Ethology, \\ The University of Tokyo, Bunkyo-ku, Tokyo \\ 113, Japan
}

\begin{abstract}
Gonadotropin-releasing hormone $(\mathrm{GnRH})$ neurons were examined immunohistochemically in the brain of mature female Shiba goats with a monoclonal antibody to GnRH (LRH-13, Park and Wakabayashi, Endocrinol. Jpn. 33: 257-272, 1986). In all animals, GnRH immunoreactive neurons exhibited a complex morphology consisting of round (49.6\%), multipolar (39.8\%) or fusiform (10.6\%) cell bodies and fibers with beaded varicosities. GnRH cell bodies were distributed rostrally from the diagonal band of Broca and medial septum, passing through the medial and lateral preoptic areas, and caudally ending within the ventromedial anterior hypothalamic areas. A majority (62.6\%) of GnRH cells were found in the preoptic areas adjacent to the organum vasculosum of the lamina terminalis, and relatively few cells $(7.1 \%)$ were distributed in the arcuate nucleus or its vicinity. Preoptic GnRH neurons project their fibers to the tubero-infundibular sulcus of the median eminence by at least 2 routes: (1) the majority of fibers were observed in the periventricular area and the arcuate neuclus (periventricular pathway), and (2) less prominent ones were found in the anterior and ventrolateral hypothalamus (ventrolateral pathway). In addition to these hypothalamic regions, GnRH immunoreactive fibers were also found in the neurohypophysis.

Key words: GnRH, Immunohistochemistry, Hypothalamus, Shiba goat.
\end{abstract}

(J. Reprod. Dev. 38: 133-142, 1992)

$\mathbf{T}_{\mathrm{i}}^{\mathrm{h}}$ he Shiba goat (Capra hircus) is a Japanese indigenous goat of which a closed colony has long been established for experimental uses [1]. This goat has been employed in various research fields including reproductive physiology [2]. Recently, we have developed a method for precisely approaching the central nervous system of the Shiba goat [3] based on the brain atlas with stereotaxic coordinates (Shimada et al., unpublished), that enabled us to attempt a neuroendocri-

Accepted for Publication: April 25, 1992

Correspondence: Y. Mori nological study on regulatory mechanisms of hypothalamic GnRH neurons [4, 5]. In the course of the study it became of exceptional importance to determine the distribution of GnRH neurons in the brain and to compare it with those reported in other mammalian species such as man [6], monkey $[7,8]$, sheep [9], cattle [10], rat [11], guinea pig [12] and mouse [13]. In the present study we examined the distribution pattern as well as the morphological characteristics of GnRH neurons immunohistochemically identified in the hypothalamus and adjacent areas of the female Shiba goat. 


\section{Materials and Methods}

Five mature female Shiba goats (\#934, \#943, \#952, \#959, \#961, 2-10 years old) were used. They were deeply anesthesized with $30 \mathrm{mg} / \mathrm{kg}$ sodium pentobarbital following systemic heparinization $(5,000$ units/head, i.v.), and then perfused bilaterally via the carotid arteries with 31 of $0.9 \% \mathrm{NaCl}$ (the first 11 of saline containing 10 units/ml heparin), followed by 2.51 of Zamboni's fixative (4\% paraformaldehyde, $7 \%$ saturated picric acid in $0.1 \mathrm{M}$ phosphate buffer, $\mathrm{pH}$ 7.4). Following perfusion, the brain and pituitary were carefully removed from the cranium and blocked. The blocks of brain were then stored in the fixative containing $15 \%$ sucrose at $4 \mathrm{C}$ over-night.

The brain block including the hypothalamus was cut at $40 \mu \mathrm{m}$ coronally on the plane of the goat stereotaxic atlas (Shimada et. al. unpublished data) on a freezing microtome, whereas the pituitary was cut sagittally. Every sixth section was processed for GnRH immunohistochemistry. Freefloating sections were washed in $0.1 \mathrm{M}$ phosphate buffered saline containing $0.05 \%$ Triton X-100 (PBST) and then incubated in PBST containing $1 \%$ normal horse serum for $40 \mathrm{~min}$ to minimize nonspecific staining. Sections were exposed to the primary antiserum (LRH-13 [14]) at a dilution of 1: 3,000 in $0.1 \mathrm{M} \mathrm{PBST}$ for $40 \mathrm{~h}$ at $4 \mathrm{C}$, and were then treated at room temperature sequentially with a biotinylated horse antimouse $\operatorname{IgG}$ for $1 \mathrm{~h}$, $0.3 \%$ hydrogen peroxidase for $30 \mathrm{~min}$ to reduce endogenous peroxidase activity and the avidinbiotin-horseradish peroxidase complex for $1 \mathrm{~h}$, with a commercial kit (Vectastain ABC kit, Vector Laboratories, Burlingame, CA U.S.A.). The horseradish peroxidase activity was demonstrated using $0.05 \%$ 3,3'-diaminobenzidine tetrahydrochloride (POLYSCIENCES, Warrington, PA, U.S.A.) and $0.01 \%$ hydrogen peroxidase as the chromogen. Sections were then mounted, dehydrated, and coverslipped. Next every sixth section was stained with cresyl violet to identify nuclear boundaries.

The specificity of the LRH-13 was previously characterized [14]. In the present experiment the immunohistochemical specificity of this antibody was verified with an antibody (antiserum to luteinizing hormone-releasing hormone-human thyroglobulin, UCB Bioproducts, S.A. Belgium, at a dilution of 1: 5,000 in $0.1 \mathrm{M}$ PBST) having a different epitope from LRH-13. Its immunoreactive products were the same as those shown with LRH-13 (data not shown). All sections were examined under a light microscope with a bright field, and sketched with a stereoscopic microscope and a camera lucida.

Postmortem examination of the ovaries of the perfused goats revealed that \#952 had 2 small corpora lutea, \#961 2 developed corpora lutea and 2 medium follicles, and \#934, \#943 and \#959 small follicles without corpus luteum.

\section{Results}

\section{Morphology of GnRH neurons}

With the sensitive LRH-13 antibody to GnRH it was possible to visualize $\mathrm{GnRH}$-immunoreactive (GnRH-IR) neurons in all the animals examined. GnRH-IR neurons were darkly stained against a low background. The cell bodies and fibers immunoreactive to LRH-13 are designated as GnRHIR cell bodies and fibers, respectively. Immunoreactive products were observed in the cytoplasm but not in the nucleus. Most of the immunoreactive cell bodies had "dendrite-like" processes. These processes were irregular in outline and often branched (Fig. 1). Immunoreactive GnRH fibers appeared as thin fibers with beaded varicosities. In individual animals $256-420 \mathrm{GnRH}$ IR cells were observed, and the GnRH-IR cells were classified into 3 morphological types: fusiform, round, and multipolar, (Fig. 1A-F, Table. 1). The majority were round $(49.6 \%)$ and multipolar $(39.8 \%)$, but there were fewer fusiform cells (10.6\%). Some GnRH-IR cell bodies and fibers

Table 1 Classification of immunoreactive GnRH cells

\begin{tabular}{crcc}
\hline & \multicolumn{3}{c}{ cell type (\%) } \\
\cline { 2 - 4 } Goat No. (n) $)^{\text {a }}$ & fusiform & round & multipolar \\
\hline $934(256)$ & 6.9 & 52.9 & 40.2 \\
$943(420)$ & 10.7 & 50.2 & 39.1 \\
$952(268)$ & 16.7 & 45.8 & 37.5 \\
$959(332)$ & 8.4 & 47.3 & 44.3 \\
$961(408)$ & 10.3 & 51.9 & 37.8 \\
\hline mean & 10.6 & 49.6 & 39.8 \\
\hline
\end{tabular}

a) Number of immunoreactive GnRH cells observed. 


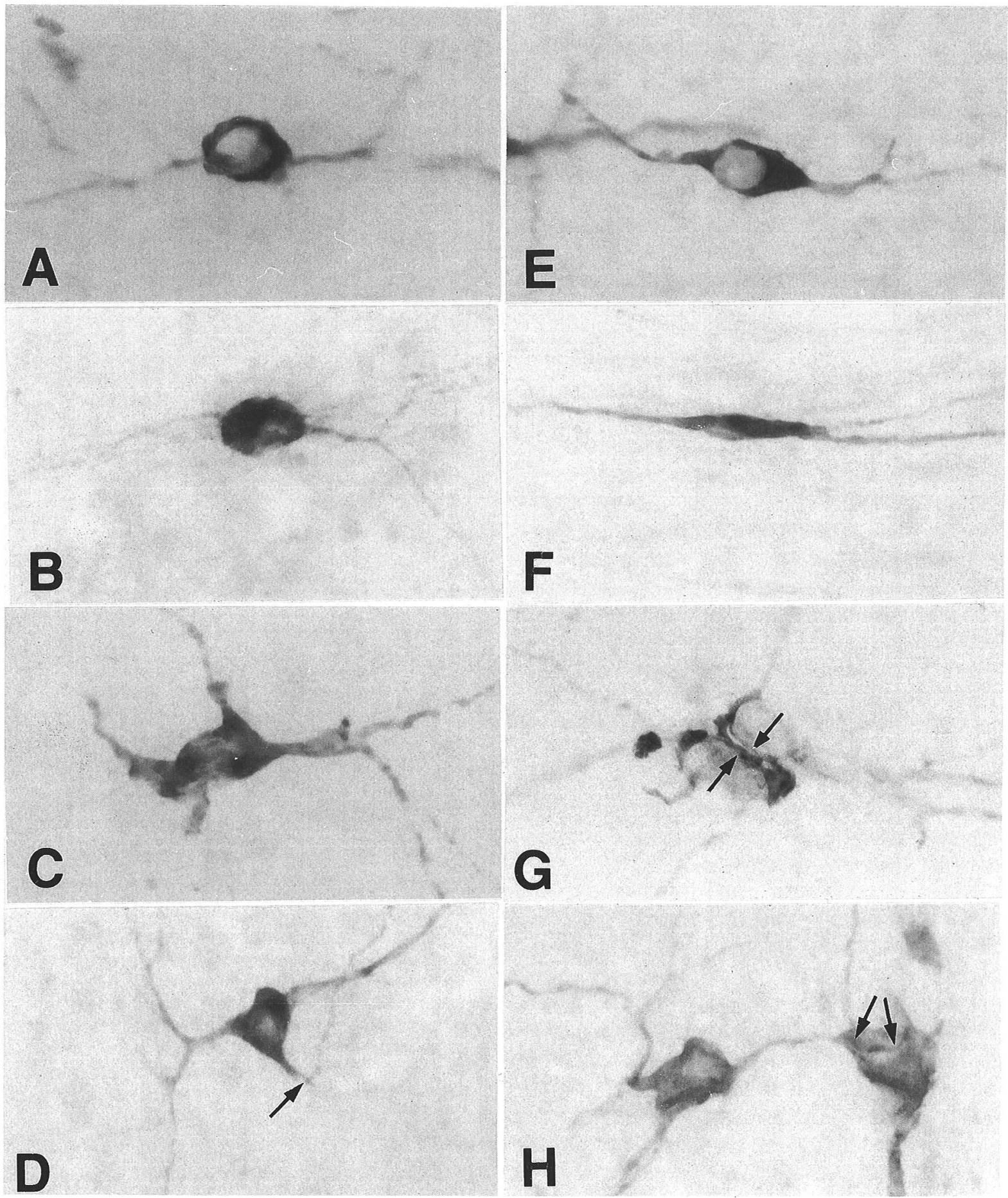

Fig. 1. Photomicrographs $(\times 560)$ of GnRH-immunoreactive (IR) cells of the "round" (A, \#961; B, \#934), "multipolar" (C, \#961; D, \#934), and "fusiform" (E, \#943; F, \#934) types. Close somatic apposition between adjacent GnRH-IR cells (G, \#961) and between GnRH-IR fiber and GnRH-IR cell body (D, \#934; H, \#943) in the MPOA are shown by arrows. 
were seen in close association with others, i.e. the cell body-cell body (Fig. 1G) or fiber-cell body (Fig. $1 \mathrm{H})$ contacts, but the frequency was rather low.

\section{Distribution of GnRH cell bodies}

The majority of GnRH-IR cell bodies were found in the medial preoptic area, at the level of the organum vasculosum of the lamina terminalis (OVLT, Fig. 2, 3A). GnRH-IR cells were distributed extending rostrally and dorsally with those in the medial septum and caudally with those in the anterior hypothalamus and the ventromedial hypothalamus. Few cells were seen in and around the arcuate nucleus, and in and above the supraoptic nucleus. Considerable numbers of GnRHIR cells were seen in the medial preoptic nucleus. Although the total number of observed GnRH-IR cell bodies varied from one animal to another, the pattern of distribution of GnRH-IR cells in the brain was similar in all of them (Table 2). The preoptic area consistently contained the highest proportion of GnRH cells (62.6\%) and the arcuate nucleus the lowest $(7.1 \%)$.
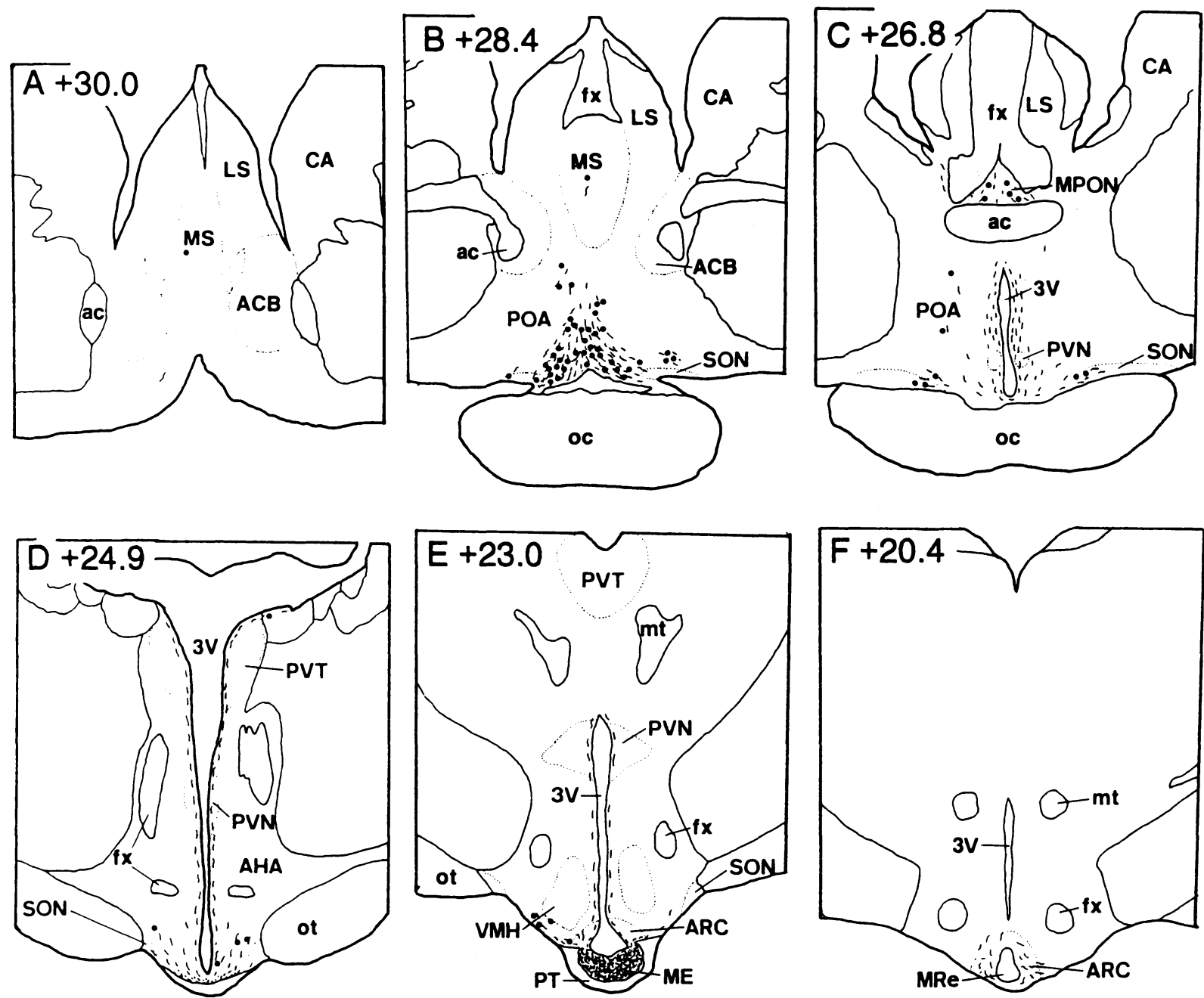

Fig. 2. Distribution of GnRH-IR cells (solid circles) and fibers (short solid lines) in drawings of coronal brain sections, rostral to caudal (A-F), through the POA and the hypothalamus. The figures show the rostro-caudal distance of the corresponding plate from the vertical plane passing through the interaural line. Abbreviations: ac, anterior commissure; ACB, septal accumbens nucleus; AHA, anterior hypothalamic area; ARC, arcuate nucleus; CA, caudate nucleus; fx, fornix; ir, infundibular recess; is, infundibular stalk; LS, lateral septal area; MPOA, medial preoptic area; MPON, medial preoptic nucleus; MRe, mammillary recess; MS, medial septum; mt, mammillothalamic tract; oc, optic chiasm; ot, optic tract; OVLT, organum vasculosum of the lamina terminalis; PD, pars distalis; PI, pars intermedia; PN, pars nervosa; POA, preoptic area; PT, pars tuberalis; PVN, paraventricular nucleus; PVT, paraventricular thalamic nucleus; $\mathrm{SON}$, supraoptic nucleus; $\mathrm{VMH}$, ventromedial hypothalamic nucleus; $3 \mathrm{~V}$, third ventricle. 


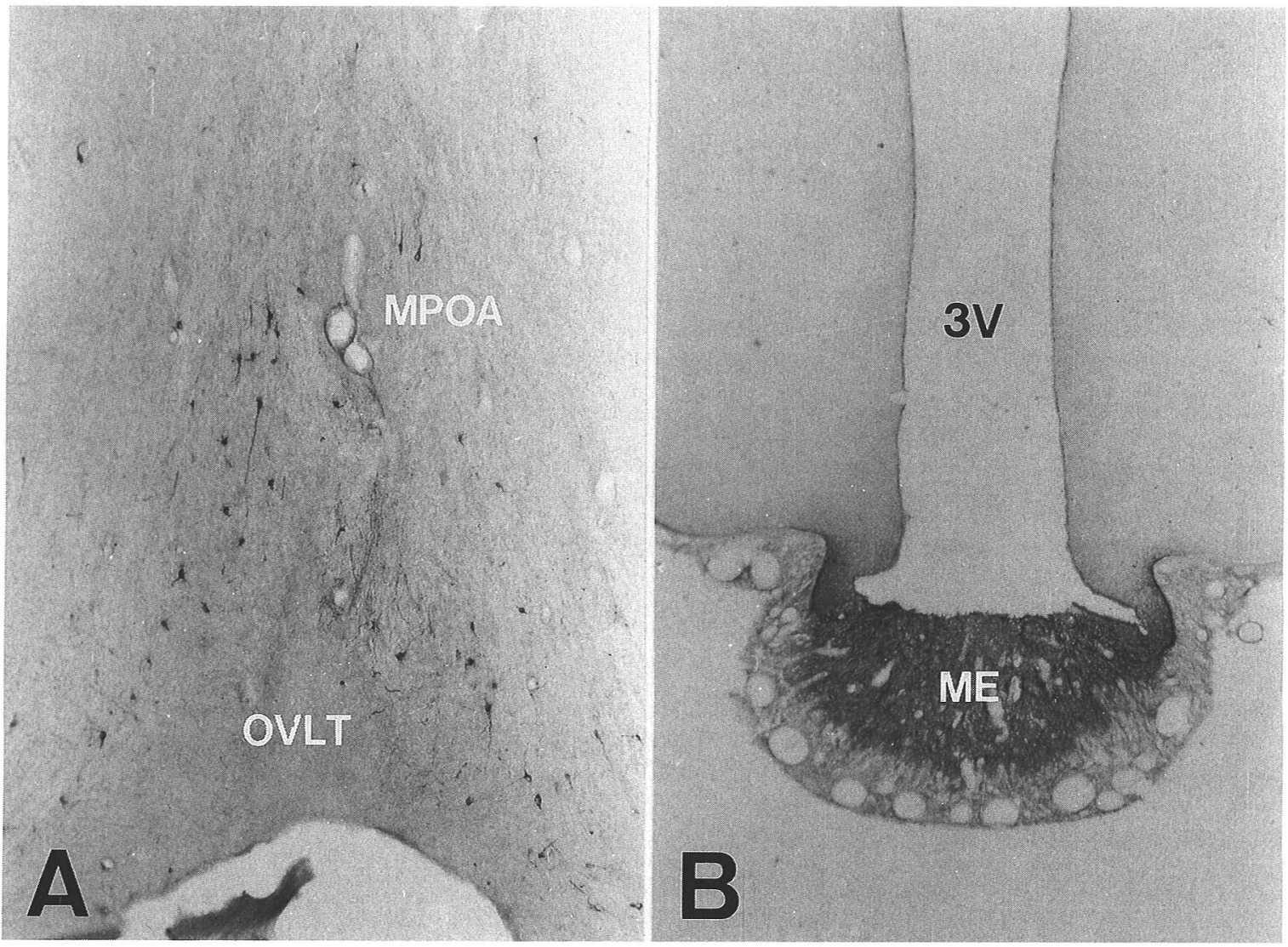

Fig. 3. A) A photomicrograph $(\times 42)$ of GnRH-IR cells in the MPOA at the level of the OVLT. GnRH-IR cells were densely located in this region. \#943. B) A photomicrograph (×21) of GnRH-IR fibers in the ME. Many GnRH-IR fibers terminated in this region. \#961. Abbreviations, see Fig. 2.

Table 2 Distribution of immunoreactive GnRH cells (\%)

\begin{tabular}{crrccc}
\hline Goat No. (n) $^{\mathrm{a}}$ & hDBB-MS & POA & AHA-LH & ARC-ME & others \\
\hline $934(256)$ & 7.0 & 56.2 & 23.0 & 9.0 & 4.8 \\
$943(420)$ & 10.2 & 59.8 & 21.2 & 6.9 & 1.9 \\
$952(268)$ & 4.1 & 66.1 & 20.1 & 7.8 & 1.9 \\
$959(332)$ & 5.7 & 60.6 & 25.3 & 6.0 & 2.4 \\
$961(408)$ & 3.2 & 70.1 & 16.9 & 5.9 & 3.9 \\
\hline mean & 6.0 & 62.6 & 21.3 & 7.1 & 3.0 \\
\hline
\end{tabular}

a) Number of immunoreactive GnRH cells observed. hDBB-MS, horizontal limb of diagonal band of Broca-medial septum; POA, preoptic area; AHA-LH, anterior hypothalamic arealateral hypothalamus; ARC-ME, arcuate-median eminence

\section{Distribution of GnRH fiber tracts and terminal} fields

GnRH-IR fibers which probably originated in the preoptic area and anterior hypothalamus projected to the median eminence and infundibular stalk (Fig. 3B) by at least 2 separate pathways: one is the periventricular pathway, and the other the ventrolateral one. The former, which contained the majority of fibers leaving in the preoptic area, coursed periventricularly in the medioventral part of the preoptic area and the anterior hypothalamus. These fibers travelled caudally along the wall of the third ventricle and then 


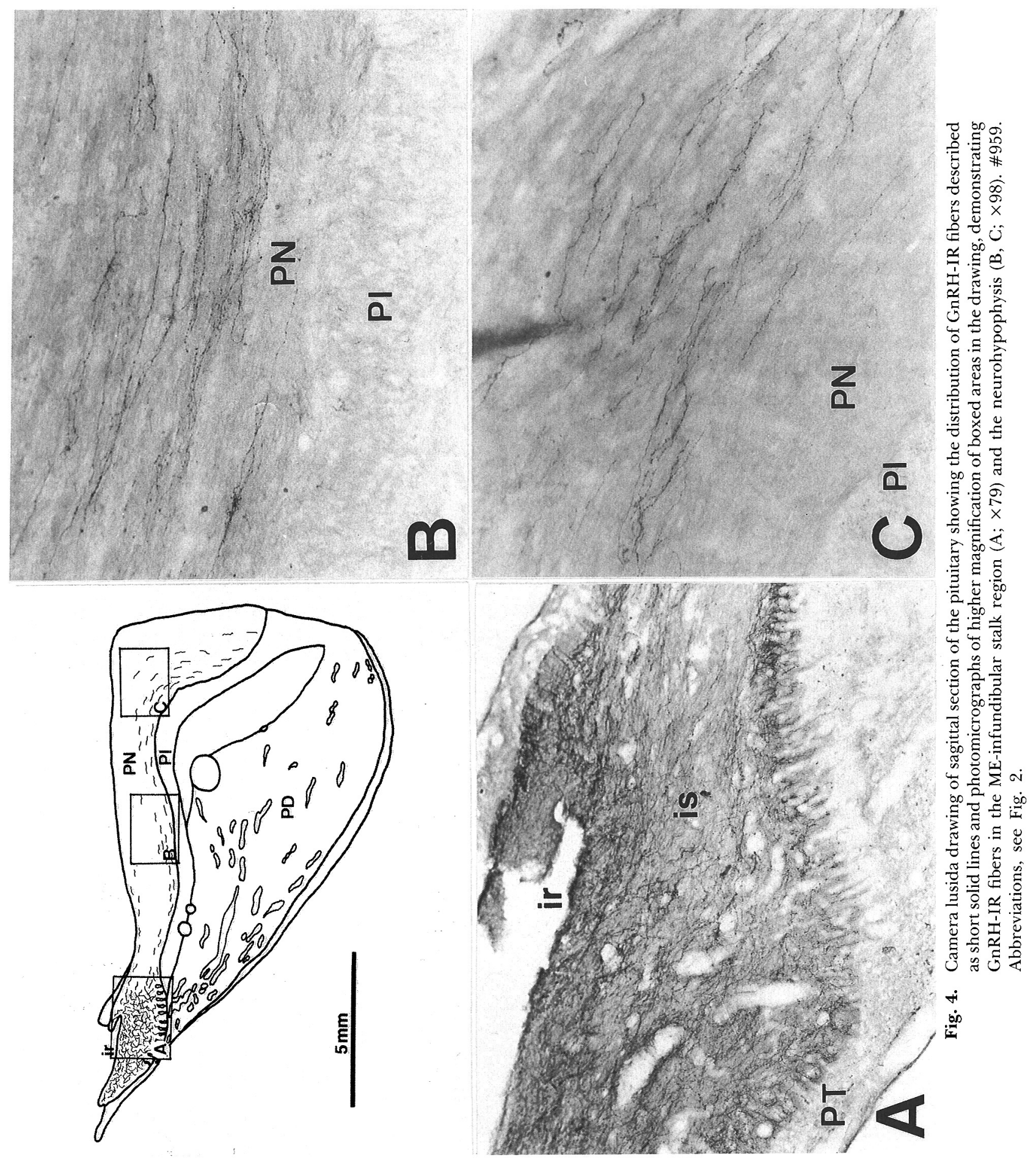


coursed ventrally to the median eminence. The other fibers in the periventricular pathway were also seen in the arcuate nucleus, and more caudally in the mammillary body. Some fibers were seen in close association with the ependymal layer of the third ventricle in the periventricular area, especially in the OVLT.

The second major pathway of GnRH-IR fibers (the ventrolateral pathway), probably originated in the preoptic area and the anterior hypothalamus including the supraoptic nucleus, passed through the region just above the supraoptic nucleus and the lateral hypothalamic area, and terminated in the median eminence and other caudal targets.

In the neurohypophysis a considerable number of GnRH-IR fibers entered from the infundibular stalk into deeper portions of the posterior hypophysis (Fig. 4). These fibers coursed along the dorsal border of the pars intermedia and some of them reached ventrocaudal portions of the neurohypophysis.

\section{Discussion}

In the present study, GnRH neurons were examined immunohistochemically in the hypothalamus of the mature female Shiba goat. Immunoreactive GnRH was found in the cytoplasm of the cell body and in the fibers with beaded varicosities as reported in other mammalian species [15], suggesting that GnRH is synthesized and stored in the cytoplasm and transported through the fibers with beaded varicosities to the nerve terminal for neurosecretion.

The majority of GnRH-IR cell bodies were found in the medial preoptic area, at the level of the OVLT, but a few cells were observed in the mediobasal hypothalamus $(\mathrm{MBH})$. The distribution in goat was similar to those reported in sheep [9], cattle [10], rat [11], guinea pig [12] and mouse [13] brain, but different from those in man [6] and monkey $[7,8]$ in which many GnRH cells are present in the MBH. GnRH-IR fibers were found mainly in the OVLT, periventricular regions, median eminence, and lateral basal hypothalamus at the level of the supraoptic nucleus as reported in sheep [9] and other mammals [15, 16]. These pathways, namely the septo-preopticoinfundibular pathways [15], were categorized into 2 routes [9, 16]: the periventricular and the ventrolateral pathways. In the Shiba goat most of the fibers coursed periventricularly in the preoptic area and anterior hypothalamus projecting to the median eminence, whereas in the sheep the major pathway was a ventrolateral one [9] although the distribution of GnRH cell bodies was similar to that in the Shiba goat brain.

GnRH-IR cell bodies were morphologically classified into 3 types: round (49.6\%), multipolar $(39.8 \%)$ and fusiform (10.6\%), as shown in Fig. 1 and Table 1 . In the rat brain, GnRH-IR cell bodies are mostly fusiform but they are further classified into 2 sub-types: "smooth" and "thorny" of highly irregular outline [17-24]. It was suggested that the "thorny" GnRH-IR neurons with irregular surfaces might receive a larger number of synaptic inputs than the "smooth" neurons $[18,19]$, but no difference has been found either in the incidence of synapses or in the density of the synaptic input as measured per unit of neuronal membrane [23]. It has been suggested that the "thorny" type could be more actively engaged in peptide processing and packaging since the content of various subcellular organelles was shown to be different in the 2 morphological types [23]. In the Shiba goat, many GnRH cells have branching dendrites and very irregular content. Similar results were reported in the sheep [9]. If the spreading pattern and the number of the processes reflect the neuronal activity or secretory activity, multipolar neurons could be more active than any other cell types. However, there was no particular distribution pattern of $\mathrm{GnRH}$ cells of each category implying any functional-morphological relationship.

The effects of gonadal steroids on the morphology of GnRH-IR cells were reported in rats. The proportion of thorny cells was increased in both males and females at puberty [22] and decreased after gonadoectomy [20]. The effects of estradiol on the GnRH immunoreactive neurons were examined in ovariectomized ewes treated with estradiol-17 $\beta\left(\mathrm{E}_{2}\right)$, and the percentage of $\mathrm{GnRH}$ cell bodies of multipolar type was approximately twice that in untreated control ewes [25]. In this study, the proportion of GnRH cell bodies was similar in all the animals, and this may be because no animal was thought to be under a strong influence of $\mathrm{E}_{2}$ according to the results of postmortem examination of ovaries.

Regarding the cell-cell or cell-fiber contacts of 
GnRH-IR neurons, similar results were reported in the man [6], sheep [9], cattle [10] and rat [11] at light microscopic levels. Synaptic contacts were demonstrated between GnRH neurons in the rat at electron microscopic levels, implying the morphological basis for autoregulation of the GnRH system [26, 27]. It was also observed that the GnRH-IR terminals made synaptic contact on estrogen receptor immunoreactive perikarya in the guinea pig [28]. Thus, these results suggest that GnRH not only plays a role as a gonadotropin releasing hormone, but also as a neuromodulator.

In the Shiba goat, GnRH-IR fibers were found in the neurohypophysis along the pars intermedia, some of them reaching caudal and ventral portions of the neurohypophysis (see Fig.4). Similar results were reported in other mammals, such as man, monkey, bat and ferret [29], although the function of the pituitary GnRH-IR fibers remains largely unknown. In the rat, however, the neurohypophysis lacks the GnRH-IR fibers, and this may have been one of the reasons why the functional study on neurohypophysis $\mathrm{GnRH}$ was hindered. Hypothesized functions are as follows, (1) GnRH acts as a neuromodulator affecting secretion of hormones of the pars nervosa and/or pars intermedia, (2) GnRH neurons contact neurovascular system in the neural-lobe to release $\mathrm{GnRH}$ into the peripheral blood as a source of immunoreactive and biologically active GnRH [30-32], (3) GnRH reaches the gonadotropes of the pars distalis through the vessels from the pars nervosa to the pars distalis. GnRH has also been demonstrated in the neurohypophysis of fish among submammalian vertebrates [33-35]. In some teleost fishes, a direct innervation of GnRH terminals to pituitary gonadotropes has been demonstrated $[36,37]$ whereas $\mathrm{GnRH}$ is delivered to gonadotropes of the pars distalis by portal vessels in higher vertebrates. GnRH fibers of the neurohypophysis may, therefore, be more primitive neuroendocrine derivatives.

\section{Acknowledgements}

The authors thank Dr. K. Wakabayashi, Gunma University and Dr. M.K. Park, University of Tokyo for their generous gift of the LRH-13 monoclonal antibody. This work was supported in part by grants given to Y.M. $(01760237,02454101)$ by the Ministry of Education, Science and Culture, Japan.

\section{References}

1. Kano Y, Sawasaki T, Oyama T. Biological characteristics of miniature "Shiba" goats. Exp Anim 1977; 26: 239-246 (In Japanese).

2. Mori Y. Central integration of photoperiodicity for gonadotropin release in ruminants. In: Yokoyama A (ed.), Brain Control of the Reproductive System. Japan Sci. Soc. Press/CRC Press Tokyo/Boca Raton 1992.

3. Mori Y, Takeuchi Y, Shimada M, Hayashi S, Hoshino K. Stereotaxic approach to hypothalamic neuclei of the Shiba goat with radiographic monitoring. Jpn J Vet Sci 1990; 52: 339-349.

4. Mori $\mathbf{Y}$, Nishihara $\mathbf{M}$, Tanaka T, Shimizu $\mathbf{T}$, Yamaguti M, Takeuchi Y, Hoshino K. Chronic recording of electrophysiological manifestation of the hypothalamic gonadotropin-releasing hormone pulse generator activity in the goat. Neuroendocrinology 1991; 53: 392-395.

5. Tanaka T, Mori Y, Hoshino K. Hypothalamic GnRH pulse generator activity during the estradiol-induced LH surge in ovariectomized goats. Neuroendocrinology 1992; (in press).
6. King JC, Anthony ELP, Fitzgerald DM, Stopa EG. Luteinizing hormone-releasing hormone neurons in human preoptic/hypothalamus: Differential intraneuronal localization of immunoreactive forms. J Clin Endocrinol Metab 1985; 60: 88-97.

7. Silverman AJ, Antunes JL, Ferin M, Zimmerman EA. The distribution of luteinizing hormonereleasing hormone ( $\mathrm{LHRH}$ ) in the hypothalamus of the Rhesus monkey. Light microscopic studies using immunoperoxidase technique. Endocrinology 1977; 101: 134-142.

8. Silverman AJ, Antunes JL, Abrams GM, Nilaver G, Thau R, Robinson JA, Ferin M, Kray LC. The Luteinizing hormone-releasing hormone pathways in Rhesus and Pigtailed monkeys: New observations on thick, unembedded sections. J Comp Neurol 1982; 211: 309-317.

9. Lehman MN, Robinson JE, Karsch FJ, Silverman AJ. Immunocytochemical localization of luteinizing hormone-releasing hormone (LHRH) pathways in the sheep brain during anestrus and mid-luteal phase of the estrous cycle. J Comp Neurol 
1986; 244: 19-35.

10. Leshin LS, Rund LA, Crim JW, Kiser TE. Immunocytochemical localization of luteinizing hormone-releasing hormone and proopiomelanocortin neurons within the preoptic area and hypothalamus of bovine brain. Biol Reprod 1988; 39: 963-975.

11. Merchenthaler I, Görcs T, Sétáló G, Petrusz P, Flerkó B. Gonadotropin-releasing hormone (GnRH) neurons and pathways in the rat brain. Cell Tissue Res 1984; 237: 15-29.

12. Silverman AJ. Distribution of luteinizing hormone-releasing hormone $(\mathrm{LHRH})$ in the guinea pig brain. Endocrinology 1976; 99: 30-41.

13. Hoffman GE, Knigge KM, Moynihan JA, Melnyk V, Arimura A. Neuronal fields containing luteinizing hormone releasing hormone $(\mathrm{LHRH})$ in mouse brain. Neurosci 1978; 3: 219-231.

14. Park MK, Wakabayashi K. Preparation of a monoclonal antibody to common amino acid sequence of LHRH and its application. Endocrinol Japon 1986; 33(2): 257-272.

15. Silverman AJ. The gonadotropin-releasing hormone (GnRH) neuronal systems: Immunocytochemistry. In: Knobil $\mathrm{E}$ and Neill J (eds.), The Physiology of Reproduction. New York: Raven Press; 1988: 1283-1304.

16. King JC, Tobet SA, Snavely FL, Arimura AA. LHRH immunopositive cells and their projections to the median eminence and organum vasculosum of the lamina terminalis. J Comp Neurol 1982; 209: 287-300.

17. Krisch B. Two types of luliberin-immunoreactive perikarya in the preoptic area of the rat. Cell Tissue Res 1980; 212: 443-455.

18. Jennes L, Stumpf WE, Sheedy ME. Ultrastructural characterization of gonadotropin-releasing hormone (GnRH)-producing neurons. J Comp Neurol 1985; 232: 534-547.

19. Liposits ZS, Sétáló GY, Flerkó B. Application of the silver-gold intensified 3,3'-diaminobenzidine chromagen to the light and electron microscopic detection of the luteinizing hormone releasing hormone system of the rat brain. Neuroscience 1984; 13: 513-525.

20. Wary S, Hoffman G. Postnatal morphological changes in rat luteinizing hormone releasing hormone neurons correlate with sexual maturation. Neuroendocrinology 1986; 43: 93-97.

21. Wary $\mathbf{S}$, Gainer $\mathbf{H}$. Effect of neonatal gonadectomy on the postnatal development of LHRH cell subtypes in male and female rats. Neuroendocrinology 1987; 45: 413-419.

22. Witkin JW. Morphology of luteinizing hormone releasing hormone neurons as a function of age and hormonal condition in the male rat. Neuroendocrinology 1989; 49: 344-348.
23. Witkin JW, Demasio K. Ultrastructural differences between smooth and throny gonadotropin releasing hormone neurons. Neuroscience 1990; 34(3): 777-783.

24. Ichikawa M. Gonadotropin-releasing hormone neurons in the olfactory system. In: Yokoyama A (ed.), Brain Control of the Reproductive System. Japan Sci. Soc. Press/CRC Press Tokyo/Boca Raton 1992.

25. Glass JD, Mastran T, Nett TM. Effects of estradiol and progesterone on the gonadotropin releasing hormone-immunoreactive neuronal system of the anestrous ewe. Brain Res 1986; 381: 336-344.

26. Leranth CS, Segura LMG, Palkovits M, Maclusky NJ, Shanabrough M, Naftolin F. The LH-RHcontaining neuronal network in the preoptic area of the rat: Demonstration of LH-RH-containing nerve terminals in synaptic contact with LH-RH neurons. Brain Res 1985; 345: 332-336.

27. Pelletier G. Demonstration of contacts between neurons staining for LHRH in the preoptic area of the rat brain. Neuroendocrinology 1987; 46: 457-459.

28. Langub Jr MC, Maley BE, Watson Jr RE. Ultrastructural evidence for luteinizing hormonereleasing hormone neuronal control of estrogen responsive neurons in the preoptic area. Endocrinology 1991; 128: 27-36.

29. Anthony ELP, King JC, Stopa EG. Immunocytochemical localization of luteinizing hormone releasing hormone in the median eminence, infundibular stalk and neurohypophysis. Cell Tissue Res 1984; 236: 5-14.

30. Seyler Jr LE, Reichlin S. Luteinizing hormonereleasing factor (LRF) in plasma of postmenopausal women. J Clin Endocrinol Metab 1973; 37: 197-203.

31. Seyler Jr LE, Reichlin S. Episodic secretion of luteinizing hormone-releasing factor (LRF) in the human.J Clin Endocrinol Metab 1974; 39: 471-478.

32. Elkind-Hirsch K, Ravnikar V, Schiff I, Tulchinsky D, Ryan KJ. Determinations of endogenous immunoreactive luteinizing hormone-releasing hormone in human plasma.J Clin Endocrinol Metab 1982; 54: 602-607.

33. Dubois MP, Billard R, Breton B, Peter RE. Comparative distribution of somatostatin, LH-RH, neurophysin, and $\partial$-endorphin in the rainbow trout: An immunocytological study. Gen Comp Endocrinol 1979; 37: 220-232.

34. Münz H, Stumpf WE, Jennes L. LHRH systems in the brain of platyfish. Brain Res 1981; 221: 1-13.

35. Dufour S, Pasqualini C, Kerdelhué B, Fontaine YA. Presence and distribution of radioimmunoassayable LHRH in the European eel, Anguilla anguilla. Neuropeptides 1982; 3: 159-171.

36. Peute J, de Bruyn MGA, Seldenrijk R, van Oordt 
PGWJ. Cytophysiology and innervation of gonadotropic cells in the pituitary of the black molly (Poecilia latipinna): An electron microscopical study. Cell Tissue Res 1976; 174: 35-54.
37. Ekengren B, Lindahl K, Fridberg G. Immunocytology and innervation of the gonadotropic cells in the teleost fish Rutilus rutilus. Acta Zool (Stockh) 1978; 59: 125-133. 